\title{
Uterine Metabolism of the Pregnant Guinea Pig as a Function of Gestational Age
}

\author{
STEVEN M. BLOCK, ROBERT L. JOHNSON, JOHN W. SPARKS, AND \\ FREDERICK C. BATTAGLIA \\ Division of Perinatal Medicine, Departments of Pediatrics, Obstetrics-Gynecology, and Physiology, University of \\ Colorado School of Medicine, Denver, Colorado 80262; and the Department of Pediatrics. The Bowman Gray \\ School of Medicine, Winston-Salem North Carolina 27103
}

\begin{abstract}
During the last half of pregnancy, the fetal guinea pig grows exponentially at $7.1 \%$ day. In order to define the metabolic requirements of the gravid uterus during this period of rapid growth, catheters were placed in the femoral artery and uterine vein of guinea pigs at gestational ages ranging from 40 days to term (68 days). The animals were studied in the unstressed state after full recovery from surgery and anesthesia. Arterial and venous concentrations of oxygen, glucose, lactate, acetoacetate, $\beta$ hydroxybutyrate, and acetate were measured, and metabolic quotients and coefficients of extraction were calculated. The glucose/oxygen quotient did not change significantly in the last half of pregnancy averaging 1.26 , while the lactate/oxygen quotient remained unchanged at $\mathbf{- 0 . 4 2}$, and the (glucose + lactate)/oxygen quotient remained unchanged at 0.82 . Coefficients of extraction of glucose and oxygen increased linearly with gestational age. The increase in supply of substrates for the rapid growth of the conceptus toward the end of gestation is accounted for by increasing extraction of substrate and by greatly increasing blood flow with increasing gestation. While glucose remains the major metabolic fuel of the guinea pig conceptus and acetate is consistently taken up by the uterus, these substrates alone cannot account for the metabolic fate of the oxygen taken up and fall far short of the predicted nutritional requirements of the fetus for both oxidative metabolism and growth. (Pediatr Res 23: 45-49, 1988)
\end{abstract}

\section{Abbreviations}

AV, arteriovenous

FFA, free fatty acid

GA, gestational age

The guinea pig is of particular interest for studies of the metabolic and cardiovascular demands of pregnancy because it produces a remarkably large fetal mass which, at term, may account for as much as $50 \%$ of the mother's prepregnant weight $(1,2)$. Recently, methodology for the chronic catheterization of this species has been developed (3-8), permitting metabolic and cardiovascular studies in conscious, unstressed animals.

Previous studies from this laboratory (4-6, 8-10) have suggested that the period around 50 days gestation may be of particular metabolic interest. Placental blood flow remains ap-

Correspondence and reprints John W. Sparks, M.D., Department of Pediatrics, Box B-199, University of Colorado Health Sciences Center, 4200 East Ninth Avenue, Denver, CO 80262

Supported by NIH Program Grant HD-00781. S.M.B. was supported by NIH Training Grant HD-07186. proximately constant until about 50 days, after which it increases as a function of spontaneous fetal weight. A number of metabolic changes also occur after that time, including alterations in blood substrate concentrations and glucose turnover rates $(4,9,10)$. The purpose of the present study is to determine gestational changes in metabolism of the gravid uterus in pregnant guinea pigs under comparably unstressed conditions. The data obtained in the present study for late gestation guinea pigs have been coupled with data reported previously for animals of less than 50 days gestation (6).

\section{METHODS}

Hartley strain guinea pigs were obtained from a commercial breeder with pregnancy timed within one day by date of exposure to the male. Animals were fed ad libitum a solid guinea pig diet enriched with vitamin $\mathrm{C}$. At gestational ages ranging from 38 to 55 days, the animals were anesthetized, and the systemic arterial and uterine venous circulations were catheterized using the surgical and anesthetic methods previously described from this laboratory $(4,6,8)$. The method for catheterization of the uterine vein was modified in that the catheter material used was polyurethane (Microrenethane, Braintree Scientific, 0.034 OD $\times$ 0.023 ID) rather than polyvinyl, in order to reduce clot formation.

The animals were studied 48 to $72 \mathrm{~h}$ postoperatively, allowing sufficient time for recovery from surgery. Daily food intake and blood substrate concentrations had returned to control levels in the study animals. Four sets of maternal arterial and uterine venous blood samples were withdrawn simultaneously at 20-min intervals beginning at $0900 \mathrm{~h}$ on the day of study. Oxygen, glucose, lactate, acetate, $\beta$-hydroxybutyrate, and acetoacetate concentrations were measured in each sample. The movement of the guinea pig was unrestricted, and the animal was allowed free access to food and water during the simultaneous withdrawal of the arterial and venous samples. Approximately $1.1 \mathrm{ml}$ of blood was withdrawn for each set of arterial and venous samples. Between sampling, the animals were transfused with an equal volume of guinea pig blood. After the four sets were obtained, the catheters were flushed with a concentrated solution of heparin $(200 \mathrm{U} / \mathrm{ml})$ and sealed. The animals were studied daily in this manner for as many days as possible. After the venous catheter ceased to draw, the animals were sacrificed using an intravenous injection of euthanasia solution. An autopsy was performed to verify the positions of the catheters. The uterus and its contents were dissected and weighed. Gestational ages were confirmed using the growth curves of Draper (1).

Chemical analyses. Oxygen content was measured with a Lex$\mathrm{O}_{2}$-Con (Lexington Instruments) initially, and later with an OSM2 hemoximeter (Radiometer). Measurements of oxygen content by either method yielded comparable values. Glucose, 
lactate, acetoacetate, and $\beta$-hydroxybutyrate concentrations were measured with standard enzymatic methods (11). Acetate was measured by an endpoint enzymatic method (6). Oxygen content was measured in duplicate, and substrate concentrations were measured in triplicate for each of the four blood samples from each of the sampling sites.

Calculations. The AV differences from the four sets of measurements were averaged, and the mean values were used as a single point for calculations of metabolic quotients on each study day. The metabolic quotients were calculated as the molar ratio of the AV substrate concentration difference divided by the AV oxygen concentration difference multiplied by a molar constant which is the number of mmoles of oxygen required to completely oxidize $1 \mathrm{mmol}$ of substrate (6). The coefficients of extraction were calculated as:

coefficient of extraction

$$
=\frac{\text { arteriovenous substrate difference }}{\text { arterial substrate concentration }} \times 100
$$

Statistics. Data were analyzed with standard statistical methods. Either paired or unpaired Student's $t$ tests were used to determine differences between means, as designated. Regression lines were calculated using a standard least squares method. Regression equations for linear, log, power, and exponential plots were calculated and the curve for any set of data was chosen on the basis of the best fit. The regression line for the plot of the arteriovenous oxygen difference against [ $6 \times(\mathrm{AV}$ glucose difference)] was calculated by using Bartlett's three group method for model II regression, because the values on both axes are subject to error and neither can be regarded as an independent variable (12). Analysis of significance for correlation coefficients was performed using hypothesis testing for correlation coefficients. Values are expressed as mean \pm SEM unless otherwise noted. The values of ratios, including substrate/oxygen quotients, are presented as mean $\pm 95 \%$ confidence limits.

\section{RESULTS}

Seventeen pregnant guinea pigs (gestational age $=38$ to 54 days) were prepared with indwelling catheters and allowed to recover for at least $48 \mathrm{~h}$. The animals were studied a total of 32 times at gestational ages ranging from 40 to 63 days. Eight of the animals were studied once; nine were studied on more than one day. One of the guinea pigs was studied on five occasions over a period of 8 days. Some of the data for animals of less than 50 days gestation have been reported previously (6). The characteristics of all of the study animals are presented in Table 1, including gestational ages and the weights and number of fetuses. The mean food intake was $34.1 \pm 9.2 \mathrm{~g} \cdot \mathrm{kg}^{-1} \cdot \mathrm{day}^{-1}$ (mean \pm $\mathrm{SD}$ ), in agreement with our previous measurements. Table 2 presents the gestational age of the animals, the AV differences of oxygen and glucose, the coefficients of extraction of oxygen and glucose, the glucose/oxygen quotients, and the oxygen saturations in the uterine vein.

Figure $1 \mathrm{~A}$ demonstrates a significant increase in oxygen extraction with increasing gestational age $(r=0.84, p<0.001)$. However, the correlation between the number of fetuses and the coefficient of extraction of oxygen was not significant $(r=0.40$, $p>0.1)$. The increasing extraction of oxygen was reflected in the oxygen content of the uterine venous blood, which fell significantly over gestation $(r=0.83, p<0.001)$ (Fig. $1 B$ ), and an increase in the AV difference of oxygen content $(r=0.71, p$ $<0.001$ ).

The AV difference of glucose concentration increased linearly with gestational age $(r=0.435, p<0.01)$ as did the coefficient of extraction of glucose $(r=0.70, p<0.001)$. The change in the coefficient of extraction of glucose is shown in Figure 2. The maximal extraction did not exceed $25 \%$. The mean glucose/ oxygen quotient was $1.26 \pm 0.05$. Before 50 days the glucose/ oxygen quotient was $1.27 \pm 0.07$; after 50 days it was $1.26 \pm$ $0.04(p>0.05)$. There was no correlation between gestational age and the glucose/oxygen quotient $(r=0.1563, p>0.1)$.

Lactate was produced by the pregnant uterus throughout gestation. The mean venoarterial lactate difference was $0.478 \pm$ $0.082 \mathrm{mmol}$ and did not change significantly with gestational age $(r=0.096)$. The mean lactate/oxygen quotient was $-0.48 \pm$ 0.08 . The mean (glucose + lactate)/oxygen quotient was $0.82 \pm$ 0.14 .

Mean AV differences of acetoacetate and $\beta$-hydroxybutyrate were $0.006 \pm 0.004$ and $0.014 \pm 0.012 \mathrm{mmol}$, respectively. Their quotients were $0.008 \pm 0.005$ and $0.02 \pm 0.015$, respectively. Neither the AV differences nor quotients were significantly different from zero.

Acetate showed an increasing AV difference with increasing gestational age $(r=0.7283, p<0.001)$. The coefficient of extraction of acetate was $22.6 \pm 4.4 \%$ and did not change with increasing fetal maturity $(r=0.0364)$. The acetate/oxygen quotient was $0.05 \pm 0.01$ and did not increase with gestational age.

Table 1. Characteristics of guinea pigs studied

\begin{tabular}{|c|c|c|c|c|c|c|c|c|c|}
\hline \multirow[b]{2}{*}{ Animal } & \multirow[b]{2}{*}{$\begin{array}{c}\text { GA at } \\
\text { sacrifice } \\
\text { (days) }\end{array}$} & \multicolumn{4}{|c|}{ Data for entire uterus } & \multicolumn{4}{|c|}{ Data for catheterized horn } \\
\hline & & $\begin{array}{c}\text { Wt of } \\
\text { total } \\
\text { uterus }\end{array}$ & $\begin{array}{l}\text { No. of } \\
\text { fetuses }\end{array}$ & $\begin{array}{l}\text { Total } \\
\text { fetal } \\
\text { wt }(g)\end{array}$ & $\begin{array}{c}\text { Total } \\
\text { placental } \\
\text { wt }(\mathrm{g})\end{array}$ & $\begin{array}{l}\text { Wt of } \\
\text { horn } \\
\text { (g) }\end{array}$ & $\begin{array}{l}\text { No. of } \\
\text { fetuses }\end{array}$ & $\begin{array}{c}\text { Fetal } \\
\text { wt }\end{array}$ & $\begin{array}{c}\text { Placenta } \\
\text { wt (g) }\end{array}$ \\
\hline $81-58$ & 43 & 117.50 & 5 & 89.1 & 12.72 & 69.84 & 3 & 53.7 & 7.77 \\
\hline $81-61$ & 45 & 90.45 & 3 & 67.5 & 10.73 & 88.43 & 3 & 67.5 & 10.73 \\
\hline $81-67$ & 45 & 55.84 & 2 & 37.8 & 5.91 & 54.33 & 2 & 37.8 & 5.91 \\
\hline $82-06$ & 45 & 77.82 & 3 & 55.6 & 9.17 & 76.21 & 3 & 55.6 & 9.17 \\
\hline $82-06$ & 45 & 77.82 & 3 & 55.6 & 9.17 & 76.21 & 3 & 55.6 & 9.17 \\
\hline $82-07$ & 45 & 178.80 & 6 & 173.8 & 20.29 & 92.03 & 3 & 63.0 & 11.14 \\
\hline $82-10$ & 45 & 108.30 & 5 & 214.2 & 16.60 & 81.30 & 3 & 57.0 & 9.40 \\
\hline $82-24$ & 57 & 399.50 & 7 & 344.3 & 23.90 & 303.5 & 5 & 264.5 & 17.10 \\
\hline $82-30$ & 45 & 150.07 & 4 & 109.6 & 12.03 & 85.52 & 3 & 52.5 & 9.30 \\
\hline $82-40$ & 49 & 140.58 & 4 & 82.2 & 12.50 & 107.21 & 3 & 59.6 & 9.37 \\
\hline $82-43$ & 41 & 40.37 & 2 & 24.0 & 4.20 & 38.52 & 2 & 24.0 & 4.20 \\
\hline $87-44$ & 42 & 145.32 & 6 & 45.5 & 15.26 & 50.25 & 2 & 30.9 & 5.28 \\
\hline $82-50$ & 58 & 441.17 & 7 & 387.1 & 19.70 & 232.48 & 4 & 203.3 & 11.59 \\
\hline $82-56$ & 63 & 363.94 & 5 & 319.0 & 17.28 & 276.68 & 4 & 243.4 & 13.48 \\
\hline $83-10$ & 53 & 261.55 & 5 & 212.7 & 23.45 & 130.90 & 3 & 100.4 & 15.16 \\
\hline $83-11$ & 55 & 292.33 & 4 & 247.0 & 20.20 & 132.45 & 2 & 112.4 & 9.22 \\
\hline $83-13$ & 50 & 213.87 & 4 & 167.1 & 14.17 & 158.15 & 3 & 122.4 & 10.63 \\
\hline
\end{tabular}


Table 2. Arterial and uterine AV differences of oxygen and glucose $\left(m m o l \cdot 1^{-1}\right)$ coefficients of extraction (\%), venous oxygen saturations (\%), and glucose/oxygen quotients

\begin{tabular}{|c|c|c|c|c|c|c|c|}
\hline Animal & $\begin{array}{c}\mathrm{GA} \\
\text { (days) }\end{array}$ & $\begin{array}{c}\text { AV } \\
\text { difference } \\
\text { oxygen } \\
(\mathrm{mmol})\end{array}$ & $\begin{array}{l}\text { Coefficient } \\
\text { extraction } \\
\text { oxygen } \\
(\%)\end{array}$ & $\begin{array}{l}\text { Oxygen } \\
\text { saturation } \\
\text { uterine } \\
\text { vein }\end{array}$ & $\begin{array}{c}\text { AV } \\
\text { difference } \\
\text { glucose } \\
\text { (mmol) }\end{array}$ & $\begin{array}{l}\text { Coefficient } \\
\text { extraction } \\
\text { glucose }(\%)\end{array}$ & $\begin{array}{c}\text { Glucose/oxygen } \\
\text { quotient }\end{array}$ \\
\hline $82-43$ & 41 & 1.53 & 31 & 62.36 & & & \\
\hline $82-44$ & 41 & 1.01 & 18 & 75.04 & & & \\
\hline $82-44$ & 42 & 1.07 & 26 & 68.79 & & & \\
\hline $82-10$ & 44 & 1.32 & 22 & & 0.27 & 5 & 1.23 \\
\hline $82-04$ & 44 & 3.11 & 39 & & 0.46 & 8 & 0.89 \\
\hline $82-07$ & 44 & 2.91 & 41 & & 0.54 & 10 & 1.12 \\
\hline $82-30$ & 44 & 1.98 & 31 & & & & \\
\hline $82-06$ & 44 & 3.13 & 44 & & 0.73 & 13 & 1.41 \\
\hline $81-67$ & 45 & 2.37 & 41 & & 0.64 & 15 & 1.16 \\
\hline $82-40$ & 48 & 2.23 & 39 & & & & \\
\hline $82-40$ & 49 & 2.89 & 53 & & & & \\
\hline $83-13$ & 50 & 4.19 & 69 & 27.39 & 1.10 & 17 & 1.59 \\
\hline $83-11$ & 52 & 4.46 & 66 & 31.65 & 0.98 & 18 & 1.32 \\
\hline $83-11$ & 53 & 5.01 & 81 & 21.18 & & & \\
\hline $83-10$ & 53 & 4.09 & 71 & 25.08 & 0.84 & 16 & 1.24 \\
\hline $83-11$ & 54 & 4.49 & 71 & 26.21 & 0.75 & 16 & 1.00 \\
\hline $83-11$ & 55 & 4.20 & 84 & 14.38 & & & \\
\hline $82-56$ & 56 & 4.78 & 75 & 22.61 & 0.95 & 20 & 1.19 \\
\hline $82-56$ & 57 & 4.07 & 68 & 29.73 & 0.85 & 21 & 1.05 \\
\hline $82-50$ & 57 & 3.87 & 61 & 37.05 & 0.68 & 17 & 1.25 \\
\hline $82-24$ & 57 & 5.90 & 78 & & & & \\
\hline $82-50$ & 58 & 3.65 & 62 & 33.83 & 0.88 & 25 & 1.45 \\
\hline
\end{tabular}
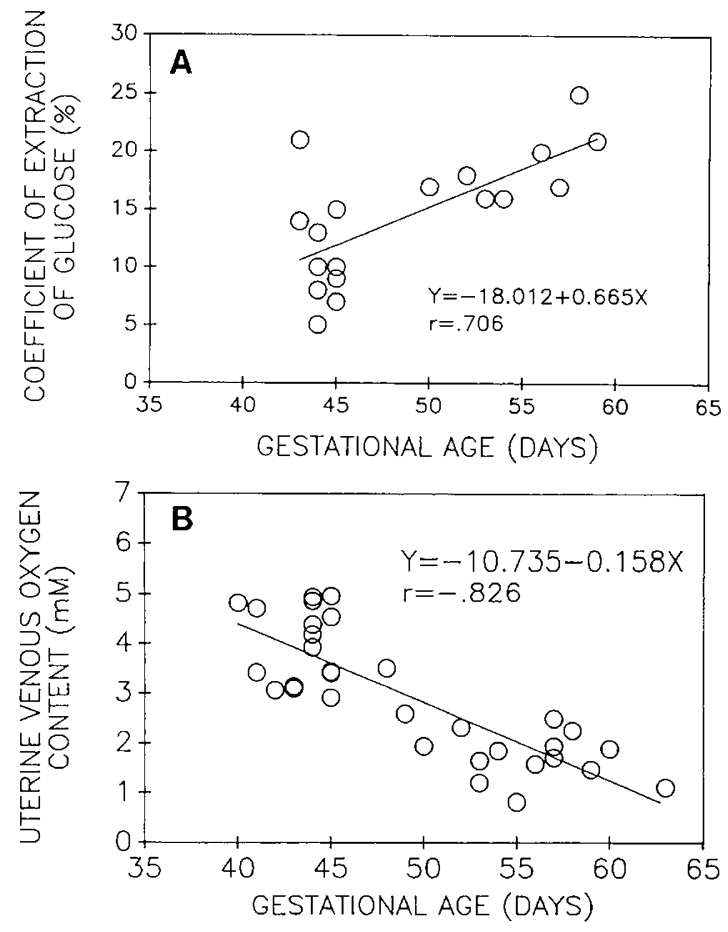

Fig. 1. Change in the coefficient of extraction of oxygen $(A)$ and uterine venous oxygen content $(B)$ with $\mathrm{GA}$.

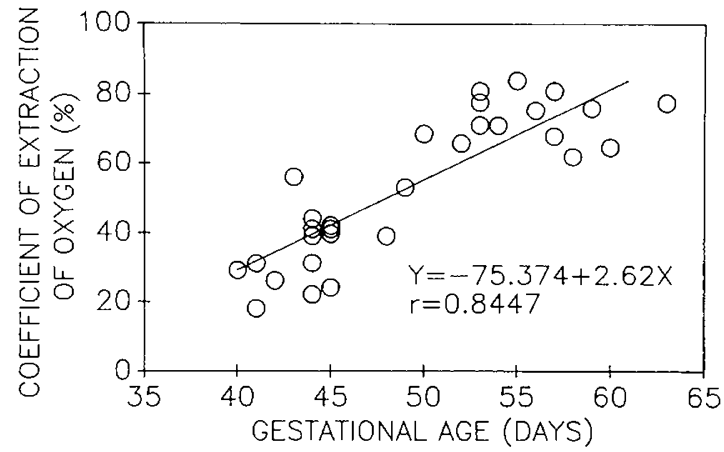

Fig. 2. Changes in the coefficient of extraction of glucose during the second half of gestation.

\section{DISCUSSION}

For reasons related to the large mass of conceptus produced, pregnancy exerts a significant metabolic and cardiovascular stress on the female guinea pig (3-7). This is particularly true in late pregnancy when the uterus is approaching maximal size. In a previous study (6) we described the metabolic quotients across the gravid uterus of the guinea pig in midgestation, but at that time we were unable to maintain pregnancy after surgery in late gestation. Herein we extend these observations to include AV extractions and substrate/oxygen quotients across the uterus during the last $25 \%$ of gestation, permitting a description of 
uterine metabolism throughout pregnancy in this species. Until the end of the third quarter of the guinea pig pregnancy, mean placental blood flow does not change significantly. In the fourth quarter of pregnancy mean placental blood flow may be approximated as a linear function until term, as shown in Figure $3 \mathrm{~A}$ extracted from our previous observations $(5,7)$. The reciprocal of the AV difference in oxygen content is an indication of the perfusion of an organ relative to its oxygen consumption (i.e. liters of blood per mmol oxygen consumed). Figure $3 B$ is a plot of this reciprocal for the uterine circulation versus gestational age illustrating that before about $75 \%$ of gestation the increasing supply of oxygen is delivered to the growing conceptus by an increased uterine oxygen extraction while flow changes little. In the last quarter of pregnancy, while the relationship of flow and extraction remains constant, the oxygen needs of the conceptus are provided by increased uterine blood flow.

The placenta of the guinea pig is able to extract oxygen from the maternal arterial circulation so efficiently that close to term the maternal venous blood has an oxygen saturation of about $25 \%$ (Fig. $1 A$ ) and may have an oxygen content as low as 1 mmol. $1^{-1}$ (Fig. $1 B$ ). This degree of extraction is the more remarkable in that it is achieved with a relatively large uterine blood flow, about $130 \mathrm{ml} \cdot \mathrm{kg}^{-1} \cdot \mathrm{min}^{-1}(5,7,8)$. In contrast, near term the sheep placenta, accompanied by uterine blood flow of about $40 \mathrm{ml} \cdot \mathrm{kg}^{-1} \cdot \mathrm{min}^{-1}$, extracts about $25 \%$ of the maternal arterial oxygen (13). The differences between the species may be accounted for by many factors, including relative size of fetal mass, growth fetal characteristics, and the sheep placenta functioning as a venous exchanger, while the guinea pig has been shown to be a countercurrent flow exchanger (14).

Glucose uptake by the pregnant uterus increases during pregnancy. This is reflected in the increase in the coefficient of extraction of glucose throughout the second half of pregnancy (Fig. 2), combined with the increase in the mean placental blood
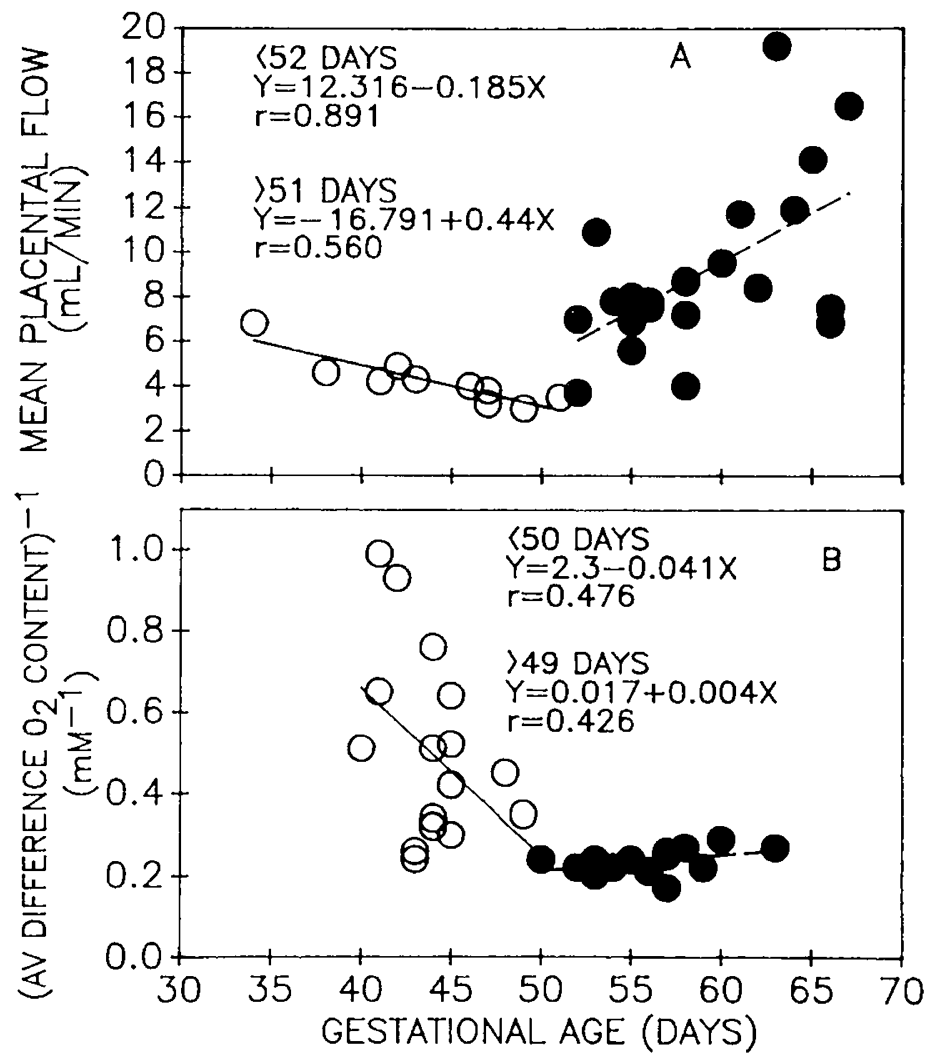

Fig. 3. Changes in the mean placental blood flow $(A)$ and (AV difference of oxygen content $)^{-1}(B)$ with changes in GA. $A$ has linear regression lines drawn for the animals less than 53 days $(O)$ and more than 50 days (-). B has linear regression lines for animals less than 51 days $(O)$ and more than 49 days $(\bullet)$. flow during the last quarter of gestation (Fig. $3 A$ ). The increased coefficient of extraction of glucose occurred despite the decrease in mean arterial glucose concentration that occurs in pregnancy $(4,9,10)$. The mean of arterial and venous glucose concentrations reflects the mean glucose concentration to which the placenta is exposed. This value decreased from $5.6 \pm 0.2 \mathrm{mmol}$ before 50 days gestation to $4.34 \pm 0.34 \mathrm{mmol}$ after 50 days gestation $(p<0.05)$. Presumably, placental permeability to glucose increases accounting for the increase in glucose extraction at decreasing glucose concentration. The increased uterine glucose uptake is consistent with the observations of Gilbert et al. (10) which showed that the glucose turnover rate increased with gestation and correlated directly with fetal mass.

When previously reported placental weight data (5-7) are combined with the present study, the placental weight increases linearly with gestation $(r=0.75, p<0.01)$. Thus, the placental tissue available for exchange of oxygen and substrates, and presumably the surface area of the maternal-fetal interface as well, increases to provide for the increased nutritional demands of the fetus.

Lactate is produced by the uteroplacenta in all species studied chronically $(6,15-18)$ and is used by the sheep fetus as a substrate for oxidative metabolism (19). It is likely that the guinea pig does not differ from other species in regard to lactate metabolism (6). Therefore, we do not consider the high production of lactate by the guinea pig conceptus as an indication of anaerobic metabolism (18).

During the last half of gestation the glucose/oxygen quotient does not change significantly with an average value of 1.26 . Figure 4 is a plot of [ $6 \times(\mathrm{AV}$ glucose difference) $]$ against $\mathrm{AV}$ oxygen difference. The slope of the regression line $(1.3,95 \%$ confidence limits of slope $=0.9-2.1$ ) represents the glucose/ oxygen quotient and is not different from the mean glucose/ oxygen quotient during the last half of pregnancy. Figure 4 illustrates that the glucose/oxygen quotient is around 1.3, irrespective of the magnitude of the AV differences of glucose and oxygen. Thus, the glucose/oxygen quotient remains constant with gestational age irrespective of the extractions of oxygen and glucose.

When the glucose/oxygen quotient is corrected for the production of lactate by the pregnant uterus, the resulting (glucose + lactate)/oxygen quotient also remains steady at $0.82 \pm 0.14$ over the last half of gestation. These data differ from the data of Peeters et al. (20) who have reported a study similar in concept to this study and our previous study. Peeters et al. (20) obtained data in guinea pigs at around 59 days gestation and calculated a (glucose + lactate)/oxygen quotient of $0.92 \pm 0.34$. In comparing their data with ours in animals of 40 to 49 days gestation who had a (glucose + lactate)/oxygen quotient of about $0.8(6)$, they concluded that as gestation progressed more glucose is utilized

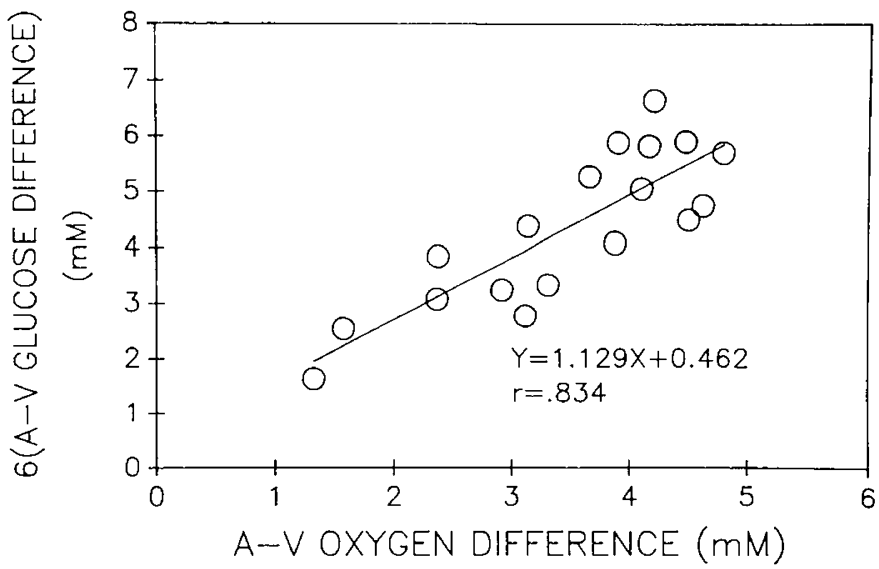

Fig. 4. AV difference of oxygen content is plotted against [6 (AV difference of glucose concentration)]. The regression line indicates the mean glucose/oxygen quotient. 
by the fetus as a carbon source. Peeters et al. (20) disturbed the chronicity of their preparation by sedating their animals and performing surgery (albeit minor) on the day before study. It is possible that the considerably increased variability of their quotients in comparison to ours is the result of instability of their model. Because of the variability of Peeters' quotients, it is unlikely that the apparent increase of their quotients at 59 days is significantly different from those calculated by us at 40 to 44 days.

In addition to the (glucose + lactate)/oxygen quotient remaining steady at 0.82 over the last half of gestation, the acetate/ oxygen quotient remained steady at 0.05 . The sum of these quotients (0.87) is far less than the theoretical sum of quotients (2.7) that we have previously estimated for the guinea pig (6). Thus, we can account for a relatively small proportion of the substrate required by the guinea pig uterus for metabolism and growth. If glucose and acetate were used entirely for oxidative metabolism, they alone would not supply sufficient substrate to account for the oxygen consumed by the uterus. Therefore, other substrates are required to serve as fuels for oxidative metabolism, as well as to provide carbon and nitrogen sources for tissue accretion (6). Since the AV difference of substrates such as amino acids has not been measured, their contributions to metabolism and tissue accretion cannot be evaluated. Peeters et al. (20) measured AV differences of FFA, but did not calculate FFA/ oxygen quotients. There was considerable variability in their results, which could be accounted for by the possible use of heparin in their animals or the lack of precision in available methods used for FFA determination. Whatever the reason for the variability, neither the present data nor previously published data are adequate to evaluate the role of FFA in the metabolism of the guinea pig fetus. This study confirms that $\beta$-hydroxybutyrate and acetoacetate do not contribute significantly to metabolism.

Using the relationships determined in the present study in conjunction with previously published work, it is possible to develop allometric relationships for the uptake of substrates by the conceptus in the second half of pregnancy in the guinea pig. We have shown in the present study that the (glucose + lactate)/ oxygen and the acetate/oxygen quotients remain constant while previous work from our laboratory has modeled the growth of tissue that occurs as an exponential function (21). Therefore, adaptations that provide for the rapid rate of growth of the conceptus in this species must provide the substrates and oxygen in relatively fixed proportions at increasing rates toward the end of gestation.

The guinea pig meets the metabolic needs of its pregnancy by greatly increasing the supply of substrates to the uterus. The products of the placental blood flow times AV differences of oxygen and of substrates (Fick principle), both of which are increasing during the last quarter of pregnancy, yield uptakes for oxygen and substrates that meet this demand. From our data, both AV differences of glucose and oxygen can be represented by the following equation:

$$
\text { AV difference } \text { (substrate or oxygen) }=\left[\left(\mathrm{k}_{1}\right)+\left[\left(\mathrm{a}_{1}\right)(\mathrm{GA})\right]\right.
$$

Similarly, uterine blood flow can be represented by:

$$
\text { flow }=\left[\left(\mathrm{k}_{2}\right)+\left(\mathrm{a}_{2}\right)(\mathrm{GA})\right]
$$

These formulae represent the regression equations of AV difference against GA or uterine blood flow against GA. Since uterine blood flow can be represented by different regression lines in the third and fourth quarters of gestation, both $k_{2}$ and $a_{2}$ will be different during the third quarter and the fourth quarter of gestation. By the Fick principle, uptake of a substrate is represented in the form of:

$$
\text { uptake }=(\mathrm{AV} \text { substrate or oxygen difference })(\text { blood flow })
$$

\footnotetext{
Thus, substituting from formulas 1 and 2, uptakes of substrates
}

or oxygen may be is represented in the form of:

$$
\text { uptake }=\left[\left(\mathrm{k}_{1}\right)+(\mathrm{a} 1)(\mathrm{GA})\right]\left[\left(\mathrm{k}^{2}\right)+(\mathrm{a} 2)(\mathrm{GA})\right]
$$

or alternatively:

$$
\text { uptake }=\left(k_{1}\right)\left(k_{2}\right)+\left(k_{1}\right)\left(a^{2}\right)(G A)+\left(k_{2}\right)\left(a_{1}\right)\left(a^{2}\right)(G A)^{2}
$$

These allometric relationships predict that the uptake of substrates or oxygen is a power function of the GA; i.e. that the uptakes of oxygen and substrates will increase in a nonlinear fashion. These relationships are consistent with the previously reported nonlinear increase in tissue accretion, which can be modeled approximately equally well with power curve or exponential functions of GA. These relationships are also in keeping with the nonlinear increase in fetal body weight in many species as reviewed by Dawes (22). While there is, of course, imprecision in knowing the exact nature of the equations relating substrate and oxygen fluxes as functions of gestational age, the above analyses demonstrate the physiologic conclusion that neither increasing blood flow nor increasing substrate extraction are alone sufficient to provide substrates in late gestation. Rather, these analyses demonstrate that the guinea pig must increase both uterine blood flow and uterine substrate extraction in order to meet the enormous metabolic and circulatory demands of pregnancy.

\section{REFERENCES}

1. Draper RL 1920 The prenatal growth of the guinea pig. Anat Rec 18:369-384

2. Ibsen HL 1928 Prenatal growth in guinea pigs with special reference to environmental factors affecting weight at birth. J Exp Zool 51:51-68

3. Peeters LLH, Grutters G, Martin CB 1980 Distribution of cardiac output in the unstressed pregnant guinea pig. Am J Obstet Gynecol 138:1177-1184

4. Sparks JW, Pegorier J-P, Girard J, Battaglia FC 1981 Substrate concentration changes during pregnancy in the guinea pig studied under unstressed steady state conditions. Pediatr Res 15:1340-1344

5. Myers SA, Sparks JW, Meschia G, Battaglia FC 1982 Relationship between placental blood flow and placental and fetal size in the guinea pig. Am J Physiol 243:H404-H409

6. Block SM, Sparks JW, Johnson RL, Battaglia FC 1985 Metabolic quotients of the gravid uterus of the chronically catheterized guinea pig. Pediatr Res 19:840-845

7. Peeters LLH, Sparks JW, Grutters G, Girard J, Battaglia FC 1982 Uteroplacental blood flow during pregnancy in chronically catheterized guinea pigs. Pediatr Res 16:716-720

8. Myers SA, Sparks JW 1987 Factors affecting radioactive microsphere measure ments of blood flow in pregnant guinea pigs. Lab Anim Sci 36:522-526

9. Gilbert M, Sparks JW, Girard JR, Battaglia FC 1982 Glucose turnover rate during pregnancy in the conscious guinea pig. Pediatr Res 16:310-313

10. Gilbert M, Sparks JW, Battaglia FC 1985 Effects of fasting on glucose turnover and metabolite levels in conscious, pregnant guinea pigs. Biol Neonate 48:8589

11. Girard JR, Chandet GS, Marliss EB, Kervran A, Rieutort M, Assan RL 1973 Fuels, hormones and liver metabolism at term and during the early postnatal period in the rat. J Clin Invest 52:3190-3200

12. Rosner B 1982 Fundamentals of Biostatistics. Duxbury Press, Boston

13. Morriss FH Jr, Rosenfeld CR, Resnik R, Meschia G, Makowski EL, Battaglia FC 1974 Growth of uterine oxygen and glucose uptakes during pregnancy in sheep. Gynecol Invest 5:230-241

14. Bailey DJ 1974 Counter-current flow of maternal and foetal blood-streams in guinea pig placenta. J Physiol (Lond) 242:104P

15. Burd LI, Jones MD Jr, Simmons MA, Makowski EL, Meschia G, Battaglia FC 1975 Placental production and foetal utilization of lactate and pyruvate. Nature 254:710-711

16. Comline RS, Silver M 1976 Some aspects of uteroplacental metabolism in cows with indwelling umbilical and uterine vascular catheters. J Physiol (Lond) 260:57!-576

17. Johnson RL, Gilbert M, Block S, Battaglia FC, Meschia G 1986 Uterine oxygen and substrate uptakes in the pregnant rabbit under chronic steady state conditions. Am J Obstet Gynecol 154:1146-1151

18. Sparks JW, Hay WW Jr, Bonds D, Meschia G, Battaglia FC 1982 Simultaneous measurements of lactate turnover rate and umbilical lactate uptake in the fetal lamb. J Clin Invest 70:179-192

19. Hay WW Jr, Myers SA, Sparks JW, Wilkening RW, Meschia G, Battaglia FC 1983 Glucose and lactate oxidation rates in the fetal lamb. Proc Soc Exp Biol Med 173:553-563

20. Peeters LLH, Martensson L, van Kreel BK, Wallenburg HCS 1984 Uterine arterial and venous concentrations of glucose, lactate, ketones, free fatty acids and oxygen in the awake pregnant guinea pig. Pediatr Res 18:11721175

21. Sparks JW, Girard JR, Callikan S, Battaglia FC 1985 Growth of the fetal guinea pig: physical and chemical characteristics. Am J Physiol 148:E132E139

22. Dawes GS 1968 Foetal and Neonatal Physiology. Year Book Medical Publishers, Chicago, pp $42-43$ 